\title{
Overcoming barriers to interprofessional education in gerontology: the Interprofessional Curriculum for the Care of Older Adults
}

This article was published in the following Dove Press journal: Advances in Medical Education and Practice

Tara J Schapmire, ${ }^{1,2}$ Barbara A Head, ${ }^{1,2}$ Whitney A Nash, ${ }^{3}$ Pamela A Yankeelov, ${ }^{2,4}$ Christian D Furman, ${ }^{1,4,5}$ R Brent Wright, ${ }^{5}$ Rangaraj Gopalraj, ${ }^{5}$ Barbara Gordon, ${ }^{6}$ Karen P Black, ${ }^{3}$ Carol Jones,' Madri Hall-Faul, ${ }^{6}$ Anna C Faul $^{2,4,7}$

'Division of General Internal Medicine, Palliative Care and Medical Education, University of Louisville School of Medicine, ${ }^{2}$ Kent School of Social Work, ${ }^{3}$ School of Nursing, ${ }^{4}$ The Institute for Sustainable Health \& Optimal Aging, University of Louisville, ${ }^{5}$ Division of Geriatric Medicine, University of Louisville School of Medicine, ${ }^{6}$ Kentuckiana Regional Planning \&

Development Agency, Louisville, KY, USA; ${ }^{7}$ Department of Social Work, University of the Free State, Bloemfontein, South Africa

\section{Video abstract}

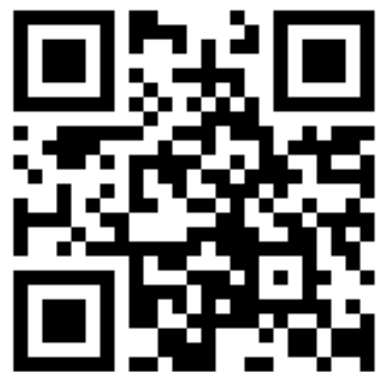

Point your SmartPhone at the code above. If you have a QR code reader the video abstract will appear. Or use: http://youtu.be/axtPfOM8Keo

Correspondence: Tara J Schapmire Med Center One, Suite 330B, IPPCCI Office, University of Louisville, 50I East Broadway, Louisville, KY 40202, USA

Tel +l 5028523738

Email tara.schapmire@louisville.edu

\begin{abstract}
A fragmented workforce consisting of multiple disciplines with varying levels of training and limited ability to work as a team often provides care to older adults. Interprofessional education (IPE) is essential for preparing practitioners for the effective teamwork required for community-based, holistic, person-centered care of the older adults. Despite numerous programs and offerings to advance education and interdisciplinary patient care, there is an unmet need for geriatric IPE, especially as it relates to community-dwelling older adults and caregivers in medically underserved areas. A core group of university faculty from multiple disciplines received funding from the Health Resources and Services Administration Geriatric Workforce Enhancement Program to collaborate with community-based providers from several Area Agencies on Aging in the creation and implementation of the Interprofessional Curriculum for the Care of Older Adults (iCCOA). This geriatric curriculum is interprofessional, comprehensive, and community-based. Learners include third-year nursing students, nurse practitioner students, third-year medical students, internal medicine and family medicine residents, master's level social work students, third-year pharmacy students, pharmacy residents, third-year dental students, dental hygiene students, community-based organization professionals, practicing community organizers, and community health navigators. This article describes the efforts, successes, and challenges experienced with this endeavor, including securing funding, ensuring equal representation of the disciplines, adding new components to already crowded curricula, building curriculum on best practices, improving faculty expertise in IPE, managing logistics, and ensuring comprehensive evaluation. The results summarize the iCCOA components, as well as the interprofessional domains, knowledge, and competencies.
\end{abstract}

Keywords: interdisciplinary education, geriatrics, team-based care, community-based care, curriculum

\section{Introduction}

A fragmented workforce consisting of multiple disciplines with varying levels of training and ability to work cohesively often provides care to older adults. Interprofessional education (IPE) is essential for preparing practitioners for the effective teamwork required for holistic, person-centered care of the older adults. According to the Education Task Force of the American Association of Colleges of Pharmacy,

IPE involves educators and learners from two or more health professions and their foundational disciplines who jointly create and foster a collaborative learning environment. The goal of these efforts is to develop knowledge, skills, and attitudes that result in interprofessional team behaviors and competence. ${ }^{1}$ 
This can be a seemingly insurmountable task for educators. In fact, intermittent exposure to other disciplines during a small number of group activities may be insufficient to achieve this goal in academic medical centers ${ }^{2}$ or communitybased educational projects. ${ }^{3}$ Comprehensive curriculum planning, development, and implementation are required for learners to become competent team members.

\section{The need for gerontology IPE}

Geriatrics is a medical specialty focused on care and treatment of older adults, while gerontology is multidisciplinary and is concerned with studying the physical, mental, and social aspects of aging. Geriatric education centers have a long tradition of promoting interdisciplinary training. ${ }^{4}$ Though the value of geriatric medical education programs is not debatable, efforts vary at different institutions. Offerings at times have covered limited disciplines such as medicine and nursing. ${ }^{5}$ Even when other disciplines such as social work and psychology are included, the numbers are small. ${ }^{6}$ Some offerings are narrowly tailored for specific geriatric syndromes such as falls ${ }^{7}$ or dementia. ${ }^{8}$ There have been successful demonstrations of limited case-specific online or virtual modules for dementia. ${ }^{8}$ While bringing many disciplines together in a formal and sustainable educational offering is challenging, it could also be rewarding. In one interprofessional, international course on aging, course participants often demonstrated improved attitude toward the aging population and improvement in their own skills and ability to work in a team. ${ }^{7}$ Despite numerous programs and offerings to advance education and interdisciplinary patient care, there is an unmet need for gerontology IPE, especially as it relates to community-dwelling older adults and caregivers in medically underserved areas. ${ }^{9}$

\section{Gerontology IPE and new approaches to care}

Geriatrics has been at the forefront of interdisciplinary care. No other specialty has the unique aspects of societal need, demographics, and medical necessity, as does the care of the older adults. The care of aging individuals is more comprehensive than the training of one discipline; therefore, experts from multiple professions are needed to form teams. When the care of the older adults is examined within settings that are either rural or underserved, the challenges for geriatric care are magnified. The vast needs of aging adults call for novel approaches to education and practice.

An emerging clinical workforce is available through community health navigators (CHNs). CHNs are individuals with case management and public health expertise who serve as the main care coordinators, bringing the clinical care teams and community care teams together to serve the needs of patients. They are the overall managers of the interdisciplinary case management plans, securing effective, coordinated service delivery. These individuals have the ability for high utilization within the interprofessional team. The benefit of this role has been demonstrated in the literature and is not a new concept as an intervention in the rural community. ${ }^{10-12}$ However, little research has been done exploring best practices surrounding the education of learners and how to integrate these key members into the interprofessional team.

\section{Challenges to gerontology IPE}

Numerous challenges prevent the successful implementation of sustained IPE in gerontology. Table 1 outlines the experiences of this program and is similar to challenges reported in the literature. Of particular interest are the consistent logistical issues that seem to emerge in the vast majority of IPE programs. Immersing learners in gerontology IPE experiences that resemble the communities in which they work is critical as it reflects the realities that exist for the older adults and the professionals serving them. This can be problematic when including higher numbers of differing programs, particularly when from more than one institution. Including experienced community-based organization professionals in the gerontology IPE is critical to this heightened IPE experience.

\section{Our response}

A core group of faculty from multiple disciplines at the University of Louisville collaborated with community-based providers from several Area Agencies on Aging (AAAs) to

Table I Challenges in providing gerontology-focused interprofessional education

Lack of designated funding sources focusing on gerontology IPE initiatives $^{21}$

Ensuring equal and appropriate representation and participation across professions ${ }^{21,31,32}$

Navigation of traditional health care hierarchy and "silo mentality"21,31-33 Addition of new or expanded content to already crowded curricula ${ }^{21,31,33}$ Pedagogical and theoretical framework challenges ${ }^{21,31}$

Limited faculty experiences teaching interprofessional concepts and content ${ }^{21,31}$

Logistical problems, including location of campuses, availability of space, appropriate selection of learner groups participating in educational activities, scheduling learning activities while considering a wide variety of programmatic schedules ${ }^{21,31,33-35}$

Ensuring comprehensive evaluation ${ }^{21}$

Abbreviation: IPE, interprofessional education. 
create and implement the Interprofessional Curriculum for the Care of Older Adults (iCCOA). The iCCOA is a gerontology curriculum that is interprofessional, comprehensive, and community-based. Learners include third-year nursing students, nurse practitioner students, third-year medical students, internal medicine and family medicine residents, master's level social work students, third-year pharmacy students, pharmacy residents, third-year dental students, dental hygiene students, community-based organization professionals, practicing community organizers, and CHNs. These disciplines were selected based on the available health profession training programs in the area. Categories of students to be involved (i.e., year in program, residents) were chosen based on the appropriateness of the content to their curriculum. Community-based organization professionals, such as practicing AAA professionals and case managers, community organizers, and $\mathrm{CHNs}$ were involved not only because they could learn more about the care of older adults but also because students of the various disciplines needed exposure to these important community-based roles. This article describes the methods used to combat the challenges of offering resulting curriculum.

\section{Methods for overcoming barriers Project aim}

The aims of the project were to 1) design an innovative, interprofessional, comprehensive, community-based, gerontology curriculum that would be effective, efficient, accepted, sustainable, and person-centric, and 2) develop an evaluation system to measure the effectiveness of the curriculum on learner outcomes. The focus of the iCCOA was on empowering learners to work in teams to provide holistic, comprehensive care to older adults and their families. This section highlights our approach to overcoming the common challenges to gerontology IPE (Table 1), which include lack of funding, ensuring appropriate interdisciplinary representation, crowded curriculum, curricular framework challenges, faculty's limited experience with teaching interprofessional curriculum, logistical problems, and need for extensive evaluation.

\section{Secured grant funding for gerontology IPE}

As stated in Table 1, a core challenge to IPE initiatives includes the lack of designated funding. Prior experience in IPE, ${ }^{13,14}$ community coalition development, ${ }^{15}$ and interventions with rural older adults ${ }^{16}$ positioned us to apply for the Health Resources and Services Administration Geriatric
Workforce Enhancement Program (GWEP) grant. In addition, the university established the Institute for Sustainable Health \& Optimal Aging to promote geriatric innovation, interdisciplinary approaches to older adult care, and workforce development. The Institute housed the GWEP to ensure interdepartmental collaboration for learners from medicine, nursing, social work, dentistry, pharmacy, law, and community health agencies. Commitment was secured from all deans and key faculty from each of the disciplines involved. Experienced national geriatric care educators in each of the disciplines were recruited as expert consultants for the project.

Our previous experience in creating the Interdisciplinary Curriculum in Oncology Palliative Education provided direction and enabled us to avoid many pitfalls as we developed the new curriculum. ${ }^{13,14}$ A detailed evaluation plan including both formative and summative measures was developed to accompany the grant proposal, based on the Plan-Do-StudyAct (PDSA) model. ${ }^{17}$

\section{Ensured equal representation of the disciplines and navigated professional hierarchy and "silo mentality"}

As noted in Table 1, IPE is challenging because of the large number of people involved and the interconnecting of various cultures. The leadership of each discipline appointed a faculty representative to be part of a planning retreat that was held shortly after the grant was awarded. Faculty members and community practitioners from each discipline contributed to all components of the curriculum to ensure relevance for all learners. There were intentional and deliberate efforts to include faculty whose professional training emphasized the biological, psychological, and social determinants of health. Additionally, all faculty had a strong interdisciplinary focus; all had experience in interdisciplinary research, clinics, or community-driven projects, often with one other; and a few held multiple professional degrees (e.g., nursing and social work, medical doctor and public health). The diversity of disciplines, experience, and trust among the faculty members allowed for a balance of perspectives to be realized in the curriculum design, preventing the tendency for the medical aspects of the curriculum to overshadow other health aspects. Adding the perspective of practitioners from the local AAA provided a balance between an academic curriculum and one that reflects community reality for the older adults.

Yet, professional cultural challenges were present throughout the development and still exist. We found ourselves grappling with what was most important to include 
in the curriculum, much like practicing interprofessional teams grapple with interprofessional care planning. Each profession compromised in what would be included in the curriculum, and no one professional set of values or cultural norms dominated. We functioned as an interprofessional team in that conflict and hierarchical issues were normal, yet resolved with open communication and mutual respect. Leadership roles were shared by all disciplines in the planning and delivery of the curriculum.

\section{Added new components to already crowded curricula}

The demands placed on professional schools for accreditation, the need for learners to meet specific competencies, and the need to cover content included in licensure tests are some of the factors contributing to crowded curricula. The iCCOA was not intended to duplicate the existing content. Faculty members developing the curriculum were asked to review the existing curricular content covering the care of older adults for their discipline, and they were asked to make recommendations for the new curriculum, which focused on interprofessional care. While the basics of geriatric care were covered by each of the disciplines in their own existing curricula, specific recommendations included topics such as community-based care of older adults, patients and families as the unit of care, social determinants of health, and medication management.

\section{Built curriculum using IPE pedagogical and theoretical frameworks}

We began the curricular development by creating clear and measurable objectives to guide the structure of all the learning experiences. These included interdisciplinary domain areas, an interprofessional knowledge base, and interprofessional competencies which are detailed in Table 2. The iCCOA objectives were developed systematically, through a comprehensive review of 1) the Geriatric Competency Grid, ${ }^{18} 2$ ) the National Consensus Project for Quality Palliative Care, ${ }^{19} 3$ ) standards of care for geriatric case management, ${ }^{20} 4$ ) Core Competencies for Interprofessional Collaborative Practice, ${ }^{21}$ 5) the National Quality Strategy's 6 priorities designed to help focus efforts and accelerate meaningful change within the health care system, ${ }^{22}$ and 6) the Partnership for Health in Aging Multidisciplinary Competencies in the Care of Older Adults at the Completion of the Entry-Level Health Professional Degree. ${ }^{23}$

Theoretical approaches to the design of the curriculum and learning experiences included adult learning theory and problem-based learning. We applied the common adult learning theory assumptions: the learner needs to first become aware of the need to know; learners are responsible and capable of self-direction; learners bring a wealth of experience to the learning activities and should be respected for their ideas and input; learners come ready to learn when they understand the rationale for learning new approaches; learners are life-centered (or task-centered) in their learning orientation; and learners are internally motivated. ${ }^{24}$ Additionally, IPE activities most often use the classic model of problem-based learning ${ }^{25,26}$ and have the following characteristics of that model: students learn from complex, real-world situations in which there is no one correct answer; students collaborate in teams to confront problems, identify gaps in care, and develop team-based solutions; students gain new information through self-directed learning; faculty act as facilitators rather than instructors; and problems presented lead to the development of clinical problem-solving abilities.

A panel of national interprofessional educators - with expertise in creating IPE learning experiences around the care of older adults - reviewed all curricular components, and their feedback was incorporated, resulting in an improved curriculum.

\section{Improved faculty expertise in IPE}

While most faculty members and educators embraced the importance of interprofessional learning, many needed to enhance their skills in teaching interprofessional practice and facilitating groups. In order to better prepare facilitators, an interprofessional faculty-led training session was held, and related materials were distributed.

During the training session, the facilitators' guides for the iCCOA were reviewed focusing on the facilitator's role. The training included instruction about responding to the learners' critical reflections in a manner that further stimulated critical thinking skills. Handouts included tips for interprofessional facilitation, ${ }^{27}$ an explanation of the Socratic teaching method, and a guide for analysis of narrative from Brown University ${ }^{28}$ to be used in responding to learner reflections.

\section{Managed logistics}

As with most interprofessional learning activities and curricula, the logistics of scheduling learners and faculty for interactive sessions was challenging. Knowing that faceto-face time with learners would be limited, we developed online didactic modules that learners could complete-at their own convenience-prior to the interactive sessions. Each discipline had their own academic calendar and requirements that had to be navigated in order to successfully bring 
Table 2 Interprofessional domains, knowledge, and competencies

\begin{tabular}{lll}
\hline Domain area & Interprofessional knowledge base & Interprofessional competencies \\
\hline & iCCOA will provide learning opportunities & By the end of this curriculum, learners will be able to do the following: \\
& which develop knowledge, skills, and attitudes \\
& needed to do the following:
\end{tabular}

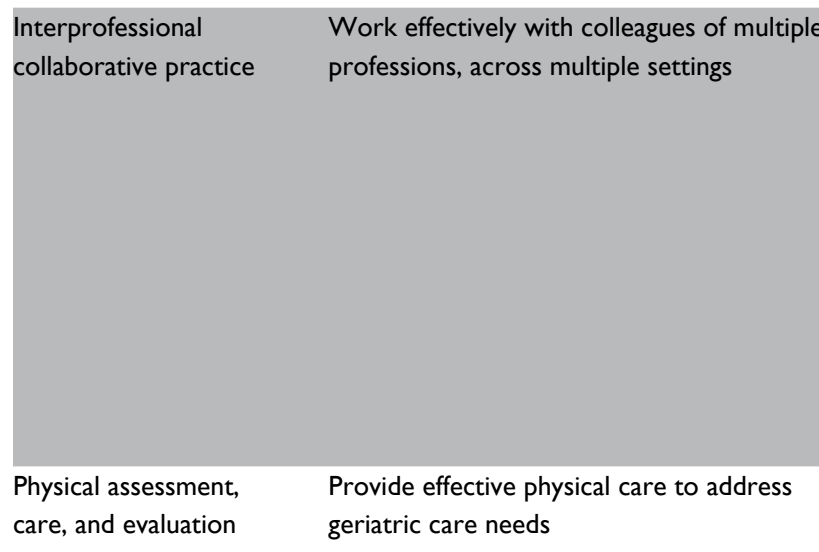

care, and evaluation geriatric care needs
Work effectively with individual of other professions to maintain a climate of mutual respect and values

Use the knowledge of one's own role and of other professions' role to appropriately assess and address the health care needs of the older adults

Communicate with patients, families, communities, and other health professionals in a responsive and responsible manner that supports a team approach to the maintenance of health and the treatment of disease

Apply relationship-building values and the principles of team dynamics to perform effectively in different team roles to plan and deliver patientcentered care that is safe, timely, efficient, effective, and equitable

Assess the physical symptoms affecting the patient

Formulate discipline-specific interventions addressing physical symptoms Construct an interdisciplinary plan of care for addressing physical symptoms

Evaluate the interdisciplinary plan of care for addressing physical symptoms and adjust when appropriate

$\begin{array}{ll}\begin{array}{l}\text { Psychosocial, spiritual, } \\ \text { and cultural assessment, }\end{array} & \begin{array}{l}\text { Provide patient/family-centered care that } \\ \text { addresses their unique psychological, spiritual, } \\ \text { care, and evaluation }\end{array} \\ \text { social, and cultural orientation and needs }\end{array}$
care, and evaluation social, and cultural orientation and needs

\section{Environmental risk} assessment, care, and evaluation
Provide patient/family-centered care that addresses the environmental risks in the care of the older adults

$\begin{array}{ll}\text { Teaching/coaching } & \begin{array}{l}\text { Provide disease management teaching and } \\ \text { coaching to older adults, their caregivers, and } \\ \text { families }\end{array} \\ \text { Ethical/legal } & \begin{array}{l}\text { Identify and address ethical and legal issues } \\ \text { impacting older adults, their caregivers, and } \\ \text { families }\end{array}\end{array}$

$\begin{array}{ll}\begin{array}{l}\text { Managing and negotiating } \\ \text { health delivery systems }\end{array} & \begin{array}{l}\text { Provide effective care transition guidance to } \\ \text { older adults, their caregivers, and families }\end{array} \\ \begin{array}{ll}\text { Communication } & \text { Communicate effectively with patients, } \\ \text { families, and colleagues }\end{array}\end{array}$

Abbreviation: iCCOA, Interprofessional Curriculum for the Care of Older Adults.

learners together. Faculty members from each discipline coordinated by the curriculum project manager were involved in the recruitment and scheduling of learners. Community organizations (AAAs) serving on the leadership team were involved in the recruitment and scheduling of communitybased professionals.
Assess the psychosocial, spiritual, and cultural needs and resources of the geriatric patient, caregiver, and family

Formulate specific interventions addressing psychosocial, spiritual, and cultural needs of the patient and family

Construct an interdisciplinary plan of care for addressing psychosocial, spiritual, and cultural needs of the geriatric patient, caregiver, and family Evaluate the interdisciplinary plan of care for addressing psychosocial, spiritual, and cultural needs of the geriatric patient, caregiver, and family and adjust when appropriate

Assess the environment within which the geriatric patient functions and determine risk factors

Formulate specific community interventions addressing the risk factors Construct an interdisciplinary community plan of care addressing the environmental risk factors

Evaluate the interdisciplinary community plan of care addressing the environmental risk factors and adjust when appropriate

Deliver quality interdisciplinary disease management education to older adults, their caregivers, and families

Apply ethical and legal principles to the practice of geriatric care

Recognize how one's own values, beliefs, and feelings influence geriatric practice

Demonstrate the ability to navigate complicated systems of care to ensure the best care possible for older adults, caregivers, and families

Demonstrate effective communication skills in interactions with older adult patients, families, caregivers, and colleagues

Completion of the curriculum was mandatory for nursing students, medical students completing their family medicine rotation, internal and family medicine residents on their geriatric medicine rotation, master's level social work students in the gerontology specialization, pharmacy students completing their advanced pharmacy practice experience, 
and pharmacy residents assigned to the university's hospital. Other groups completed the curriculum according to their instructors' recommendations or requirements and included family nurse practitioner students, social workers in their field practicum, dental hygiene and dental students, and law students.

A unique aspect of the curriculum was the inclusion of community workers (professionals from the AAAs) and health care navigators. These experienced participants served as both learners and teachers as they shared from actual experience working with older adults in the community. Community professionals used completion of the curriculum for professional continuing education credit and other training requirements.

Face-to-face iCCOA learning experiences were planned based on the schedules of the learners. Because nursing students comprised the largest group and have the least flexibility, their schedules took top priority. Flexibility was key in adjusting to the various calendars of the disciplines. Once sessions were scheduled, faculty (including community practitioners) were recruited as facilitators. Having a large pool of committed faculty was essential as faculty also have schedules and commitments to be considered. Having a designated curriculum project manager was essential to overcoming logistical challenges.

\section{Ensured comprehensive evaluation}

The iCCOA evaluation was based on the first 3 levels of Kirkpatrick's Training Evaluation model. ${ }^{29}$ According to Kirkpatrick's model, level 1 assesses participant's reactions to the learning event, level 2 assesses participants' acquired knowledge and skills, and level 3 assesses application of the acquired knowledge and skill. The online modules and the interprofessional case management experiences (ICMEs) were both evaluated at level 1; the online modules were also assessed at level 2, while the ICMEs were also evaluated at level 3. All of the evaluations and the performance measures required by the funding sponsor were included in an online registration site; this allowed all learners to register for any number of iCCOA learning activities, depending on their course requirements, needs, and time restraints.

Learner satisfaction served as the level 1 assessment and was evaluated after completion of each learning opportunity. The assessment emphasized the degree of satisfaction associated with the method of training, content, time spent per activity, thoroughness of the content, and applicability of the educational activity. The level 2 assessment of the online modules included a module-specific, faculty-developed inter- disciplinary geriatric care knowledge test which was administered prior to and directly after the completion of the online module. The level 3 evaluation of the ICMEs consisted of a pretest and post-ICME administration of the Self-Efficacy for Interprofessional Experiential Learning Scale, ${ }^{30}$ a 16-item, self-report questionnaire with 3 subscales and a Cronbach alpha of 0.96 for the total scale. Faculty and learners also provided informal feedback during leadership meetings. The study was approved by the University of Louisville Human Subjects Protection Program.

\section{Results: components of the iCCOA}

The iCCOA focuses on interprofessional domains, knowledge, and competencies (Table 2) and has 4 major components. This IPE curriculum project is still ongoing, and we are still collecting data; therefore, we present the curriculum components here.

\section{Didactic modules}

Learners complete 5 case-based online modules designed to teach the core concepts of geriatrics. Topics covered include roles of the various team members, geriatric care structure and processes, pain and symptom management, communication, grief and loss, spiritual dimensions of care, social and cultural care, motivational interviewing, interdisciplinary practice, and ethics. One module presents the model of interprofessional community-based integrated geriatric care, and one teaches motivational interviewing skills. The other modules present the care of 3 diverse patients in the community: a Hispanic man who works at the horseracing track and is diagnosed with diabetes at a health fair; an African American woman diagnosed with Alzheimer's dementia who lives with her husband with alcoholism; and an older woman with advanced cancer who is facing the end of life. Content is structured related to the care provided by an interprofessional team; therefore, learners are exposed to the role of their discipline in a patient's care, as well as developing a better understanding and respect for what other team members contribute to holistic patient care. These modules were created in an interactive software program (Softchalk) which links to videos, websites, and activities, and engages learners with questions and tasks to facilitate interactive learning. Completion of the modules is verified by learner posttest.

The online didactic modules are required of all learners and must be accomplished independently with completion time averaging 4-5 hours. They are completed prior to participation in the ICME as a means to "level" the knowledge 
base of all learners related to integrative community-based geriatric care before they interact with the other disciplines.

\section{Interprofessional case management experience}

Learners from multiple disciplines attend a face-to-face ICME session lasting 2 and a half hours. Sessions include learners from each discipline and, if possible, at least one community practitioner in small groups of 6-8 learners at each table facilitated by 1 faculty member. The project coordinator assigns learners to the small groups to ensure as many disciplines as possible are represented. Up to 5 small groups participate in each session with a lead facilitator managing the large group discussion, keeping time, and presenting content and instruction.

Learners work together in these small interprofessional groups to assess the needs of an older adult, critique video scenarios of interactions between that patient and the involved clinicians, role-play a care planning or family meeting, and develop an interprofessional care plan. Four diverse cases were developed for use during the ICME sessions (1 per session). The patients presented through case summaries and video clips include a retired lawyer with advanced prostate cancer and Alzheimer's dementia who is cared for by his partner; a disabled nursing assistant who has progressive dementia and lives alone, whose daughter works full time while also providing care; a retired farmer who has untreated diabetes, cares for his great-grandson, and has a wife with functional limitations; and an older woman who has terminal lung cancer and is cared for by her husband, who is a disabled veteran. All the patient scenarios include consideration of family issues and the challenges of providing integrated care in rural communities that are often underserved. Learners are encouraged to consider not only medical care for each patient but also the social determinants of health.

\section{Clinical experience and reflective writing exercise}

The clinical geriatric care experience varies according to discipline, but learners have a clinical experience in which they observe the care of a geriatric patient in the community. Select sites offer rural primary care where the learner participates in the care planning for a geriatric patient. Learners then write a critical reflection paper evaluating the care provided and exploring whether it reflects quality geriatric care.

Learners from multiple disciplines come together to share and discuss their experiences and reactions in small groups with the trained faculty facilitator who has read their papers and provided written feedback. This session allows the learners to share experiences and develop awareness of the various approaches and resources for geriatric care provided in the community and further learn about team members and team work. It also allows them to compare and contrast the model of care being taught to the realities in practice and explore ways to improve.

\section{Evaluation}

Prior to the pilot year, formative feedback was received from the expert panel on the 5 online modules and resulted in substantial modification. Subsequent formative feedback was solicited during the leadership meetings; gaps in the total number of learners who participated per discipline and per educational levels were discussed, and solutions were noted. Table 3 indicates some of the challenges and solutions noted in the formative feedback. Preliminary results of the summative evaluation via the satisfaction, pre-post knowledge tests, and standardized measures indicate satisfaction across the undergraduate- and graduate-level learners of the various disciplines, as well as the practicing professions. The preliminary results also show significant differences in knowledge from pre- to posttest (in a positive direction) and improved self-efficacy for interprofessional learning. Results will be published upon completion of the project.

\section{Discussion}

This article outlines our gerontology IPE efforts in creating and implementing iCCOA, a curriculum intended to improve the care of older adults and empower learners to work in teams. This process required planning, collaboration, flexibility, and constant refinement.

Those seeking to enhance their own IPE efforts can benefit greatly from the valuable insights gained by iCCOA faculty while implementing this curriculum. Faculty within the health professions should have a mutual respect for unique strengths within their training as well as an acknowledgment of limitations. A team is needed in geriatric care because there are often complexities encountered that are beyond the training of any one professional. By addressing these limitations within IPE settings, members of the team are able to become better informed regarding the expertise of professional teammates.

Our team addressed scheduling difficulties of different disciplines by applying adult learning theory in creating clinical cases that could be viewed online, in advance of ICME sessions. This online distribution promoted efficiency and learner self-direction, and allowed for individual assessment 
Table 3 Responses to formative feedback provided by expert reviewers and learners

\begin{tabular}{|c|c|}
\hline Observations that warranted attention & Modifications \\
\hline \multicolumn{2}{|l|}{ Online modules } \\
\hline $\begin{array}{l}\text { Learners experienced difficulties in navigating the registration site } \\
\text { for the online modules }\end{array}$ & $\begin{array}{l}\text { Discipline-specific directions were written and revised to address best } \\
\text { practices and frequently asked questions in the most simplistic terms }\end{array}$ \\
\hline Modules included dense, complicated interdisciplinary content & $\begin{array}{l}\text { Our adult learner experts suggested more white space and page breaks to } \\
\text { reduce the visually, dense nature of the content }\end{array}$ \\
\hline $\begin{array}{l}\text { Students and other learners requested verification of completion of } \\
\text { the modules and ICME }\end{array}$ & $\begin{array}{l}\text { Certifications of completion were generated for each successfully completed } \\
\text { online course and ICME }\end{array}$ \\
\hline $\begin{array}{l}\text { Professionals reported that the CEU/CME information was difficult } \\
\text { to locate initially }\end{array}$ & CEU/CME information was placed on the first slide of each online module \\
\hline $\begin{array}{l}\text { Law students reported being overwhelmed with the medical } \\
\text { content in online modules }\end{array}$ & $\begin{array}{l}\text { Law faculty engaged to increase law-oriented content. Law students provided } \\
\text { an in-class presentation of the content included in the online modules to } \\
\text { highlight the patient's legal/ethical needs and discuss legal remedies }\end{array}$ \\
\hline $\begin{array}{l}\text { Undergraduate- and graduate-level learners and practicing } \\
\text { professionals completed the online modules for course credit, } \\
\text { mandatory educational experience, or continuing education } \\
\text { purposes with or without CME or CEUs. Scores on posttests } \\
\text { tended to differ depending on discipline and level of education } \\
\text { across the different online modules }\end{array}$ & $\begin{array}{l}\text { The leadership team decided that the initial established aspirational posttest } \\
\text { goals were set too high for all types of learners since they represented } \\
\text { a broad range of disciplines, and because the learners ranged from } \\
\text { undergraduate to graduate level to practicing professionals. Given the } \\
\text { experts' evaluations of the trainings prior to launch, the continued support } \\
\text { of the faculty requiring the modules as course activities, and the evaluations } \\
\text { offered by the learners, the curriculum design faculty have made only minor } \\
\text { changes to the structure and content of the training modules and the ICMEs } \\
\text { and reduced posttest targets }\end{array}$ \\
\hline
\end{tabular}

\section{ICME}

Students, learners, and professionals alike reported the value of having Area Agency on Aging representatives at each ICME Faculty communicated alternate perspectives on certain interdisciplinary aspects of a few of the video vignettes, for example, the seating arrangement present during an interdisciplinary case presentation and the use of white coats by some Learners expected that the video vignettes used with the ICME were model portrayals of interdisciplinary interactions

The curriculum for medical learners is already very crowded, and any changes or additions to the curriculum are required to go to the medical school curriculum committee. There was much discussion about how the online modules could be included

The video vignettes of the ICMEs emphasize different disciplines depending on the needs of the case. A few learners from different disciplines indicated that they did not have a role in a particular case

\section{Critical reflection} In the critical reflection experience, learners observed the care of an older adult in a primary care setting, wrote a reflection, and discussed their experiences with an interdisciplinary team of learners. Many of them expected to witness the practice of care coordination as described in the online modules and were confused as to how to approach the writing task
Area Agency on Aging faculty or representative from the Aging Resource Center is included in each ICME

Facilitator's guides were modified to address these perspectives and have a brief critical reflection with the interdisciplinary learners during the ICME on the impact on the team interactions

A statement of acknowledgment was included stating the video vignettes are not stand-alone teaching tools, are not intended to be exemplary portrayals of interactions, and should be used with the related PowerPoint presentations and facilitator's guide

It was determined that revising the medical school curriculum was not possible at this time. However, the ICME could be included during the learners' AHEC rotation during the third year of medical school, if it was shortened. During the AHEC rotation, learners spend much of their time in a rural area, returning to campus for instruction during the rotation. The ICME was shortened and included in the curriculum

The video vignettes to be utilized in each ICME are chosen to be in alignment with the majority of the learners' disciplines per each ICME session, to the extent possible

The instructions to the learners were modified to acknowledge their observations may not adhere to best care coordination practices. They were also instructed to include not only a reflection of what was witnessed but also an assessment of aspects that could be included to improve the coordinated care of the older adults

Abbreviations: ICME, interprofessional case management experience; CEU, continuing education unit; CME, continuing medical education; AHEC, Area Health Education Center.

of interprofessional knowledge. At the beginning of each problem-based learning-focused ICME session, the introduction included learning about the roles and unique aspects of each discipline. This was an excellent exercise to raise awareness and sensitivity for other disciplines, while honoring the adult learning theory assumption that learners bring a wealth of knowledge and experience to the learning activities. The outside experts infused objectivity and enhanced the program offerings. The formative expert feedback, along with the formative feedback from learners, allowed us to honor 
the PDSA approach to constantly revising the curriculum. In addition, the curriculum program manager was essential and evaluated based on the repeated successful coordination of all the learner schedules and learning experiences.

A couple of unique components of the iCCOA included, first, the infusion of AAA community workers and CHNs into the various parts of the program. This partnership has allowed for very fruitful and practical discussions about the barriers and solutions learners might face when they enter into the workforce. Community workers are able to give an accurate account of how systems currently function and how they could ideally function if the right interdisciplinary approach is taken. A second unique component is the organization of the IPE through a neutral entity, such as an institute that was outside the restrictive/rigid academic structure, which helped pool resources and limit conflict, and provided a nurturing environment.

Strengths of our project included an established interdisciplinary faculty team to which other disciplines could be added, experience in creating a similar IPE curriculum, secure funding for project activities, a supportive community base through the AAA, a supportive academic community, and strong evaluation. The available programs in the area limited the disciplines involved in our curriculum, although we were fortunate to have dentistry, law, medicine, nursing, pharmacy, and social work learners. As with most IPE endeavors, we were challenged to fit the curriculum into already overcrowded curricula in each of the disciplines. Securing faculty time to facilitate the learning activities has also been a challenge not easily overcome. Our next steps will include collecting and analyzing more data and further refining and integrating the IPE into the institutional curriculum in a sustainable manner, and extending iCCOA to other national sites.

\section{Acknowledgments}

This project is supported by the Health Resources and Services Administration (HRSA) of the US Department of Health and Human Services (HHS) under U1QHP28732 titled Kentucky Rural \& Underserved Geriatric Interprofessional Education Program and is a 3-year grant of \$2.55 million. This information or content and conclusions are those of the authors and should not be construed as the official position or policy of, nor should any endorsements be inferred by, the HRSA, HHS, or the US Government. This material is based on the work supported by HRSA, which had no role in the design, methods, participant recruitment, data collection, analysis, or preparation of the manuscript or in decision to submit manuscript for publication. Aspects of this paper were presented as conference talks at the Association for Gerontology in Higher Education annual meeting in March 2017, the American Society on Aging annual conference in March 2017, and the American Geriatrics Society annual meeting in May 2017. No abstracts were published.

\section{Author contributions}

Schapmire, Head, and Faul AC conceived the model concept and design. Yankeelov had access to and analyzed the data, and took responsibility for the integrity. Schapmire and Head prepared the manuscript. All authors contributed toward data analysis, drafting and revising the paper and agree to be accountable for all aspects of the work.

\section{Disclosure}

The authors report no conflicts of interest in this work.

\section{References}

1. Buring SM, Bhushan A, Broeseker A, et al. Interprofessional education: definitions, student competencies, and guidelines for implementation. Am J Pharm Educ. 2009;73(4):1-8.

2. Jones KJ, Vandenberg EV, Bottsford L. Prevalence, formation, maintenance, and evaluation of interdisciplinary student aging interest groups. Gerontol Geriatr Educ. 2011;32(4):321-341.

3. Furze J, Lohman H, Mu K. Impact of an interprofessional communitybased educational experience on students' perceptions of other health professions and older adults. J Allied Health. 2008;37(2):71-77.

4. Institute of Medicine. Retooling for an Aging America: Building the Health Care Workforce. Vol 2017. Washington, DC: The National Academies Press; 2008.

5. Oeseburg B, Hilberts R, Luten TA, van Etten AV, Slaets JP, Roodbol PF. Interprofessional education in primary care for the elderly: a pilot study. BMC Med Educ. 2013;13:161.

6. Kamei T, Kurokawa Y, Campbell R, et al. [The evaluation of interdisciplinary team gerontological education program for health, medical and social work course students to promote interdisciplinary team approach for the elderly]. Bull St Lukes Coll Nurs. 2005;31:36-45. Japanese.

7. Clark PG, Weeks LE, van Den Bergh G, Doucet S. Gerontology across the professions and the Atlantic: development and evaluation of an interprofessional and international course on aging and health. Gerontol Geriatr Educ. 2017;38(2):141-157.

8. Cartwright J, Franklin D, Forman D, Freegard H. Promoting collaborative dementia care via online interprofessional education. Australas $J$ Ageing. 2015;34(2):88-94.

9. Health Resources \& Services Administration. HHS awards $\$ 35.7$ million to improve care for older adults. 2015. Available from: https://www. hrsa.gov/about/news/pressreleases/150713geriatricworkforce.html. Accessed October 01, 2017.

10. Loskutova NY, Tsai AG, Fisher EB, et al. Patient navigators connecting patients to community resources to improve diabetes outcomes. $\mathrm{J} \mathrm{Am}$ Board Fam Med. 2016;29(1):78-89.

11. Wang ML, Gallivan L, Lemon SC, et al. Navigating to health: evaluation of a community health center patient navigation program. Prev Med Rep. 2015;2:664-668. 
12. Doolan-Noble F, Gauld R, Waters DL, Leon De La Barra S. Patient and Health Provider Perspectives on the Provision of Chronic Illness Care in the Southern Region. Dunedin: Centre for Health Systems, University of Otago; 2012.

13. Head BA, Schapmire T, Hermann C, et al. The Interdisciplinary Curriculum for Oncology Palliative Care Education (iCOPE): meeting the challenge of interprofessional education. J Palliat Med. 2014;17(10):1107-1114.

14. Head BA, Schapmire T, Earnshaw L, et al. Evaluation of an interdisciplinary curriculum teaching team-based palliative care integration in oncology. J Cancer Educ. 2016;31(2):358-365.

15. Miller JJ, Rhema S, Faul A, et al. Strength in process: using concept mapping to inform community coalition development. J Community Pract. 2012;20(4):432-456.

16. Yankeelov PA, Faul AC, D’Ambrosio JG, Collins WL, Gordon B. "Another day in paradise": a photovoice journey of rural older adults living with diabetes. J Appl Gerontol. 2015;34(2):199-218.

17. Langley GL, Moen R, Nolan KM, Nolan TW, Norman CL, Provost LP. The Improvement Guide: A Practical Approach to Enhancing Organizational Performance. 2nd ed. San Francisco, CA: Jossey-Bass Publishers; 2009.

18. Mezey M, Mitty E, Burger SG, McCallion P. Healthcare professional training: a comparison of geriatric competencies. J Am Geriatr Soc. 2008;56(9):1724-1729.

19. National Consensus Project for Quality Palliative Care. Clinical Practice Guidelines for Quality Palliative Care. 3rd ed. Pittsburg, PA: National Consensus Project for Quality Palliative Care; 2013.

20. National Association of Professional Geriatric Care Managers. Code of Ethics and Standards of Practice. Tuscon, AZ: National Association of Professional Geriatric Care Managers; 2014.

21. Interprofessional Education Collaborative Expert Panel. Core competencies for interprofessional collaborative practice. 2011. Available from: https://www.ipecollaborative.org/resources.html. Accessed February 21, 2013.

22. National Quality Forum. Priority Setting for Healthcare Performance Measurement: Addressing Performance Measure Gaps in Care Coordination. Washington, DC: Department of Health and Human Services; 2014.

23. Partnership for Health in Aging Multidisciplinary Competencies in the Care of Older Adults at the Completion of Entry-Level Health Professional Degree. American Geriatric Society. 2010 [cited 2016 June 1]. Available from: https://www.apa.org/pi/aging/resources/ multidisciplinary-competencies.pdf. Accessed October 01, 2017.
24. Knowles MS, Holton III EF, Swanson RA. The Adult Learner: The Definitive Classic in Adult Education and Human Resource Development. 6th ed. San Diego, CA: Elsevier Science \& Technology Books; 2005.

25. Barrows HS, Tamblyn RM. Problem-Based Learning: An Approach to Medical Education. New York, NY: Springer; 1980.

26. Savin-Baden M, Major CH. Foundations of Problem-Based Learning. New York, NY: Open University Press; 2004.

27. National Center for Interprofessional Practice and Education. Preceptors in the Nexus Toolkit. 2017. Available from: https://nexusipe.org/ engaging/learning-system/preceptors-nexus-toolkit. Accessed April 28, 2017.

28. Wald HS, Reis SP, Monroe AD, Borkan JM. "The loss of my elderly patient:" interactive reflective writing to support medical students' rites of passage. Med Teach. 2010;32(4):e178-e184.

29. Kirkpatrick DL, Kirkpatrick JD. Transferring Learning to Behavior: Using the Four Levels to Improve Performance. San Francisco, CA: Berrett-Koehler; 2005.

30. Mann K, McFetridge-Durdle J, Breau L, et al. Development of a scale to measure health professions students' self-efficacy beliefs in interprofessional learning. J Interprof Care. 2012;26(2):92-99.

31. Breitbach AP, Sargeant DM, Gettemeier PR, et al. From buy-in to integration: melding an interprofessional initiative into academic programs in the health professions. J Allied Health. 2013;42(3):e67-e73.

32. Brennan CW, Olds DM, Dolansky M, Estrada CA, Patrician PA. Learning by doing: observing an interprofessional process as an interprofessional team. J Interprof Care. 2014;28(3):249-251.

33. Fook J, D'Avray L, Norrie C, Psoinos M, Lamb B, Ross F. Taking the long view: exploring the development of interprofessional education. J Interprof Care. 2013;27(4):286-291.

34. Pecukonis E, Doyle O, Acquavita S, Aparicio E, Gibbons M, Vanidestine T. Interprofessional leadership training in $\mathrm{MCH}$ social work. Soc Work Health Care. 2013;52(7):625-641.

35. Tullmann DF, Shilling AM, Goeke LH, Wright EB, Littlewood KE. Recreating simulation scenarios for interprofessional education: an example of educational interprofessional practice. J Interprof Care. 2013;27(5):426-428.
Advances in Medical Education and Practice

\section{Publish your work in this journal}

Advances in Medical Education and Practice is an international, peerreviewed, open access journal that aims to present and publish research on Medical Education covering medical, dental, nursing and allied health care professional education. The journal covers undergraduate education, postgraduate training and continuing medical education

\section{Dovepress}

including emerging trends and innovative models linking education, research, and health care services. The manuscript management system is completely online and includes a very quick and fair peer-review system. Visit http://www.dovepress.com/testimonials.php to read real quotes from published authors. 